\title{
Avaliação dos conflitos no uso da terra na bacia hidrográfica do Ribeirão Lamarão, Distrito Federal
}

\author{
Evaluation of conflict of land use in the Lamarão river watershed, Federal \\ District
}

\begin{abstract}
João Maurício Fernandes Souza', Elton Fialho dos Reis ${ }^{\mathrm{II}}$, Adilson Santos Martins ${ }^{\mathrm{III}}$, Antônio Lázaro Ferreira Santos ${ }^{\text {IV }}$
\end{abstract}

\begin{abstract}
Resumo
A falta de estudos e a constante degradação das Áreas de Preservação Permanentes (APPs) têm representado um dos maiores entraves para o planejamento de ações conservacionistas, além de favorecer o uso de estratégias inadequadas de manejo das bacias hidrográficas. Dessa forma, este estudo teve como objetivo, delimitar de maneira automática as APPs, elaborar um mapa de uso da terra e identificar a ocorrência de conflitos no uso da terra, tendo como referência legal, a Resolução n 303, do CONAMA e o Código Florestal. O estudo foi desenvolvido na bacia hidrográfica do Ribeirão Lamarão, situada no sudeste do Distrito Federal, Brasil. Para a classificação do uso da terra, foi utilizada uma imagem digital do satélite ALOS com resolução espacial de 10 metros, sensor AVNIR - 2, obtida em julho de 2010. A base cartográfica utilizada na obtenção dos dados de relevo e hidrografia foi a em formato digital na escala de 1:10.000. Foram mapeadas sete classes de uso da terra: solo exposto $(1,01 \%)$; agricultura $(50,46 \%)$; cerrado ralo $(11,28 \%)$; cerrado denso (10,45\%); pastagem (17,54\%); pivô central (7,63\%); e nuvens $(1,55 \%)$. Delimitaram-se as APPs situadas no terço superior dos morros $\left(9,94 \mathrm{~km}^{2}\right)$; nascentes e áreas de contribuição $\left(0,27 \mathrm{~km}^{2}\right)$; margens dos cursos d'água $\left(24,10 \mathrm{~km}^{2}\right)$; perfazendo um total de $34,31 \mathrm{~km}^{2}(36,85 \%)$ da área total da bacia. Não foram identificadas APPs em encostas com declividade superior a $45^{\circ}$. A área de uso indevido correspondeu a $21,70 \mathrm{~km}^{2}(63,24 \%)$, sendo as classes agricultura $(38,40 \%)$ e pastagem $(15,32 \%)$ as principais ocorrências nessas áreas. Apenas $11,50 \mathrm{~km}^{2}(33,46 \%)$ das APPs estão protegidas por vegetação nativa.
\end{abstract}

Palavras-chave: Área de preservação permanente; Geoprocessamento; APPs; Sensoriamento remoto

\begin{abstract}
The lack of studies and the constant degradation of Permanent Preservation Areas (PPA's) have represented one of the biggest barriers to the planning of conservation actions, in addition to promoting the use of inappropriate strategies for watershed management. Thus, the objective of was study map the land use, to automatically delimit the PPA's and to identify the occurrence of conflicts in land use, having as legal reference, the Brazilian Forest Code and Resolution No. 303, of CONAMA. The research has developed in the watershed of the Lamarão stream, located in the southeast of the Federal District, Brazil. For the land use classification, a digital image of the ALOS satellite with 10 - meter spatial resolution, AVNIR - 2 sensor, obtained in July 2010 has used. The relief and hydrography data used were obtained in digital format on a scale of 1: 10,000. It was possible to map seven land use classes: exposed soil (1.01\%); agriculture (50.46\%); sparse cerrado (11.28\%); cerrado dense (10.45\%); pasture (17.54\%); central pivot (7.63\%); and clouds (1.55\%). The PPA's located in the upper third of hills $\left(9.94 \mathrm{~km}^{2}\right)$; springs and their respective contributing areas $\left(0.27 \mathrm{~km}^{2}\right)$; riparian zones with width less than 10 meters $\left(24.10 \mathrm{~km}^{2}\right)$, summing $34.31 \mathrm{~km}^{2}(36.85 \%)$. There were no identified PPA's on hillsides with slopes greater than $45^{\circ}$. The area of undue use corresponded to $21.70 \mathrm{~km}^{2}(63.24 \%)$, with agriculture (38.40\%) and pasture (15.32\%) classes occupying most of this area. Only $11.50 \mathrm{~km}^{2}(33.46 \%)$ of PPA's are protected by native vegetation.
\end{abstract}

Keywords: Permanent preservation area; Geoprocessing; PPA's, Remote sensing

\footnotetext{
Engenheiro Agrícola, Dr., Professor do Departamento de Agronomia, Centro Universitário de Anápolis, Av. Universitária Km 3,5, Cidade Universitária, CEP 75083-515, Anápolis (GO), Brasil. joao.souza@unievangelica.edu.br (ORCID: 0000-0002-1945-6695)

II Engenheiro Agrícola, Dr., Professor do Departamento de Engenharia Agrícola, Universidade Estadual de Goiás, Campus Henrique Santillo, BR 153, 3105, Caixa Postal 459, CEP 75132-400, Anápolis (GO), Brasil. fialhoreis@ueg.br (ORCID: 0000-0002-8683-6735)

III Engenheiro Agrônomo, Dr., Professor do Departamento de Engenharia Agrícola, Universidade Estadual de Goiás, Campus Henrique Santillo, BR 153, № 3105, Caixa Postal 459, CEP 75132-400, Anápolis (GO), Brasil. adilson.santos@ueg.br (ORCID: 0000-0002-0527-2924)

IV Geólogo, Dr., Professor do Departamento de Engenharia Civil, Universidade Estadual de Goiás, Campus Henrique Santillo, BR 153, № 3105, Caixa Postal 459, CEP 75132-400, Anápolis (GO), Brasil. antonio.lazaro@ueg.br (ORCID: 0000-0002-1252-8780)
} 


\section{Introdução}

As consequências do uso e ocupação da terra sobre os recursos hídricos têm proporcionado modificações na paisagem e na qualidade de vida das populações, além de afetar o equilíbrio ambiental em bacias hidrográficas. Embora a importância da água para sobrevivência da humanidade, seja reconhecida pelos diferentes segmentos da sociedade, à medida que a demanda para seus diversos usos aumenta, as ações direcionadas para promover mudanças na forma predatória em que este recurso é utilizado, continuam sendo implementadas de maneira limitada (NASCIMENTO et al., 2005).

Um dos grandes desafios do homem para a conservação ambiental é concentrar esforços e recursos para a preservação e recuperação de áreas naturais consideradas estratégicas, das quais vários ecossistemas são dependentes. Dentre essas, destacam-se as Áreas de Preservação Permanente (APPs), que têm papel vital dentro de uma bacia hidrográfica, por serem responsáveis pela manutenção, preservação e conservação dos ecossistemas ali existentes (SARTORI et al., 2009).

As APPs são fundamentais para a manutenção da vegetação de determinadas áreas com o objetivo de manter inalterado o uso da terra, que deve permanecer coberta pela vegetação original (BRASIL, 2002). Atualmente, estas áreas estão submetidas a grandes extensões de degradação devido à intensificação das pressões antrópicas sobre o ambiente. Observa-se um processo de substituição das paisagens naturais por outros usos e ocupações da terra e a conversão das áreas com cobertura florestal em fragmentos florestais, causando problemas ambientais e, em muitos casos, afetando a disponibilidade de recursos naturais (LOUZADA; SANTOS, 2008).

A importância das Áreas de Preservação Permanente para manutenção da qualidade de vida da humanidade é, sem dúvida, indiscutível. Além dos aspectos legais, a Resolução no 303 do CONAMA, de 20 de março de 2003, destaca a sua função ambiental, considerando essas áreas capazes de preservar os recursos hídricos, a paisagem, a diversidade biológica, o fluxo gênico da fauna e flora, como também de garantir a estabilidade geológica, assegurar o bem-estar das populações humanas e atenuar a erosão do solo.

A legislação ambiental brasileira é considerada ampla, contudo, alguns fatores têm contribuído para torná-la pouco destra. Com destaque para a deficiência em meios e materiais para punir com rigor os ataques ao meio ambiente (NASCIMENTO et al., 2005). No caso do monitoramento das APPs, o grande desafio está sob o aspecto técnico e econômico, pois os critérios de delimitação com base na topografia exigem o envolvimento de pessoas especializadas e de informações detalhadas da unidade espacial em análise.

A utilização de Sistemas de Informações Geográficas (SIG) tem tornado possível o processamento rápido e eficiente dos dados necessários para delimitação de APPs e do estudo dos conflitos do uso e ocupação da terra, essenciais para análise das intervenções antrópicas em bacias hidrográficas. O uso dessa opção tecnológica tem se tornado relevante à medida que permite a análise do problema em grandes dimensões, complexidade e com custos para operacionalização em campo que outrora seriam elevados (SANTOS et al., 2010).

A eficácia desses procedimentos, integrada às informações produzidas a partir do uso de imagens provenientes de sensoriamento remoto, sobretudo as de média e a alta resolução espacial tem permitido identificar e mensurar a ocorrência de conflitos de uso da terra em APPs, fortalecendo as ações ambientais de monitoramento, seja como instrumento jurídico de controle e fiscalização desses ambientes, seja como ferramenta de apoio a tomada de decisões pelos órgãos responsáveis pela gestão das bacias hidrográficas (NASCIMENTO et al., 2005).

Dentro do processo de desenvolvimento econômico-social promovidos pelo governo Juscelino Kubistchek na década de 50, estabeleceu-se a necessidade de uma modificação na territorialidade, que proporcionasse a ocupação e o desenvolvimento do interior do país. Essa política desenvolvimentista gerou um paradigma de modificações sociais no país e a construção de uma nova capital concretizava a ideia do surgimento de um país moderno e com equidade 
social (FERREIRA, 2006). Assim, a transferência da capital para Brasília e a consolidação do Distrito Federal transformou intensamente as características de uso e ocupação do território brasileiro.

O ribeirão Lamarão é um dos principais cursos d'água dessa região sendo responsável pelo fornecimento de água de praticamente toda área do PAD/DF. Tendo em vista esse cenário, de intensa ocupação agrícola e importância econômica para o Distrito Federal, este estudo tem como objetivo delimitar, por meio de técnicas do geoprocessamento, as áreas de preservação permanente, bem como, identificar e avaliar a ocorrência de conflitos de usos da terra na bacia hidrográfica do ribeirão Lamarão, Distrito Federal, Brasil.

\section{Material e métodos}

\section{Aspectos físicos da área}

A bacia hidrográfica do ribeirão Lamarão está situada na região administrativa do

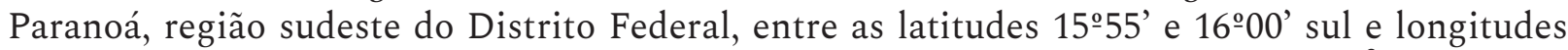

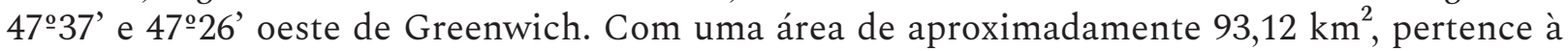
bacia hidrográfica do rio Preto, sendo o seu curso d'água principal o ribeirão Lamarão (Figura 1).

O clima predominante da região, segundo a classificação de Köppen é "tropical de Savana”, com a concentração da precipitação pluviométrica no verão. A estação chuvosa começa em outubro e termina em abril, representando $84 \%$ do total anual. O trimestre mais chuvoso é de novembro a janeiro, sendo dezembro o mês de maior precipitação do ano. A estação seca vai de maio a setembro, sendo que, no trimestre mais seco (junho/julho/agosto), a precipitação representa somente $2 \%$ do total anual. Em termos de totais anuais, a precipitação média interanual, no Distrito Federal, varia entre $1.200 \mathrm{~mm}$ a $1.700 \mathrm{~mm}$ (DISTRITO FEDERAL, 2011b).

Figura 1- Localização da bacia hidrográfica do ribeirão Lamarão, Distrito Federal, Brasil

Figure 1 - Location of the Lamarão river watershed, Federal District, Brazil

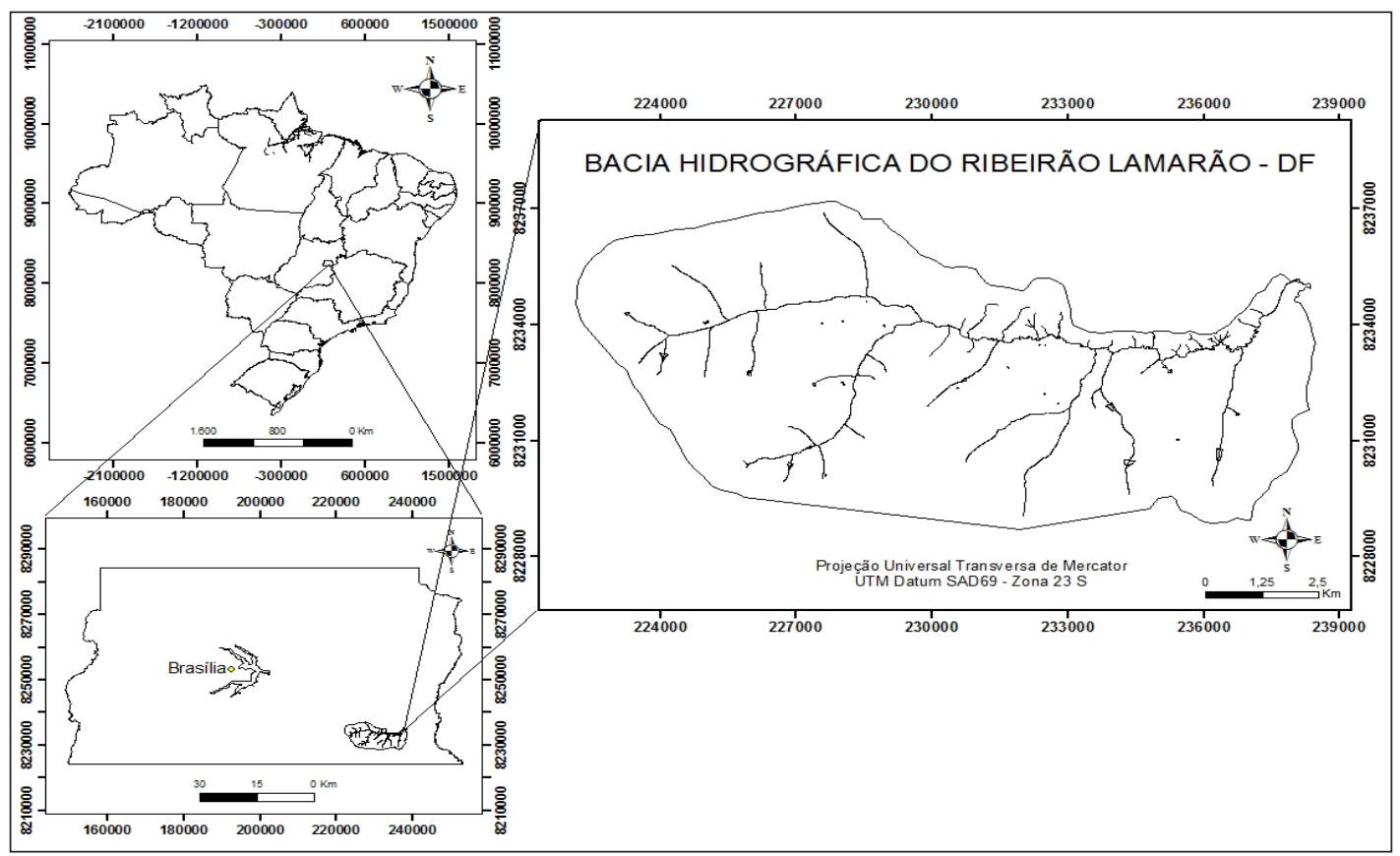

Fonte: Os autores (2012) 
De acordo com o Governo do Distrito Federal - (DISTRITO FEDERAL, 2011a), o relevo da região, localizada no extenso Planalto Central, caracteriza-se por terrenos antigos e aplainados pela erosão, que originaram chapadões. A vegetação característica é a do Cerrado, sendo que dentro do bioma Cerrado ainda é possível diferenciar algumas variações conhecidas como cerradões, cerrado sentido restrito, campos limpos, campos sujos e matas secas, contudo, grande parte da vegetação original tem sido gradualmente substituída por cultivos agrícolas e pastagens.

\section{Material utilizado}

Para a obtenção dos dados necessários à realização deste estudo, foi utilizada uma imagem digital do satélite ALOS com resolução espacial de 10 metros, sensor AVNIR - 2, obtida em julho de 2010. O sensor AVNIR-2 (Advanced Visible and Near-Infrared Radiometer - Type 2) é um sensor óptico com 4 bandas espectrais sendo três nos intervalos espectrais do visível $(0,42-0,69$ $\mu \mathrm{m})$ e uma no do infravermelho próximo $(0,76-0,89 \mu \mathrm{m})$ projetado para observação de regiões terrestres e costeiras. Suas imagens são úteis para o mapeamento do uso e cobertura da terra para fins de monitoramento ambiental, em escala regional e local (IBGE, 2011).

As bases cartográficas planialtimétricas utilizadas são em formato digital na escala de 1:10.000, digitalizadas partindo das folhas SD.23-Y-C-IV-4-SE-0C, SD.23-Y-C-IV-4-SE-D, SD.23Y-C-V-3-SO-C, SD.23-Y-C-IV-4-SE-E，SD.23-Y-C-IV-4-SE-F，SD.23-Y-C-V-3-SO-E (Sistema Cartográfico do Distrito Federal (DISTRITO FEDERAL, 1997), contendo as áreas urbanas, estradas, hidrografia, curvas de nível com equidistância de 5 metros e os pontos relativos às nascentes. O tratamento e análise dos dados foram realizados por meio dos softwares AutoCAD versão 2007 (AUTODESK, 2006), ENVI versão 4.5 (ITT CORPORATION, 2008).

\section{Classificação visual da imagem}

A imagem adquirida já havia sido previamente processada (ENGESAT, 2011), georreferenciada e ortorretificada para coordenadas geográficas, Sistema de Projeção Geográfica (UTM), Datum Horizontal Sad-69. A fim de validar o registro realizado pela empresa fornecedora do material, a base cartográfica na escala de 1:10000, foi sobreposta a imagem ALOS e a partir da seleção de 20 pontos de controle de fácil identificação, tais como: cruzamento de estradas e/ou rodovias e encontro de curso d'água foi realizado um novo georreferenciamento, obtendo-se um RMSe (Root Mean Square Error) de 0,32 pixels, não sendo identificadas incompatibilidades com a base cartográfica, optou-se por não se realizar um novo registro na imagem.

Para a geração do mapa de uso e ocupação da terra realizou-se a classificação supervisionada da imagem ALOS, utilizando a composição em falsa cor das bandas 4 (0,76- 0,89 $\mu \mathrm{m}), 3(0,61-0,69 \mu \mathrm{m}), 2(0,52-0,60 \mu \mathrm{m})$, e o algoritmo de classificação da máxima verossimilhança por meio do software ENVI versão 4.5. Essa etapa consiste na distinção dos padrões tonais e das feições da imagem, tais como tamanho, forma e textura.

Posteriormente, a região da bacia de estudo foi percorrida, objetivando identificar a fidedignidade das categorias de uso da terra geradas na classificação preliminar e também para eliminar possíveis dúvidas na classificação. Para isso foram selecionados 30 pontos de controle na imagem ALOS, os quais foram conferidos no campo com o auxílio de um de receptor GPS modelo Garmin CSx. Utilizando-se do editor de valores digitais, o ClassEdit, desenvolvido pela SULSOFT, foi possível a partir do valor numérico do pixel de uma classe, atribui-lo a outra classe, simplesmente mudando o valor numérico desse pixel. Dessa forma foram realizadas alterações de forma a tornar a classificação a mais fidedigna à realidade do campo apenas escolhendo a nova classe a ser associada a todos os pixels no polígono interpretados incorretamente durante a classificação. Com a finalidade de verificar a confiabilidade do mapa de uso da terra gerado, 
foi realizada uma avaliação da exatidão por meio do índice Kappa, conforme a equação a seguir:

$$
\mathrm{K}=(\mathrm{Po}-\mathrm{Pe}) /(1-\mathrm{Pe})
$$

Em que: $\mathrm{Po}=$ proporção global de concordância observada; $\mathrm{Pe}=$ proporção global de concordâncias esperadas pelo acaso (varia de 0 a 1 , significando total concordância entre os dados quando se obtém o valor máximo) (COHEN, 1960).

\section{Delimitação das áreas de preservação permanente (APPs)}

Para a delimitação automática das APPs utilizou-se a metodologia desenvolvida por Ribeiro et al. (2002), a partir da geração do modelo digital de elevação hidrologicamente consistente (MDEHC). Esta delimitação está fundamentada nos artigos $2^{\circ}$ e $3^{\circ}$ da resolução do CONAMA n 303/2002, e na Lei 4.771/1965, que divide as APPs em: situadas no terço superior dos morros, nas encostas com declividade superior a 45 graus, nas nascentes e suas áreas de contribuição e margens dos cursos d'água.

\section{Desenvolvimento do Modelo Digital de Elevação Hidrologicamente Consistente (MDEHC)}

Para a geração do MDEHC foram utilizadas as curvas de nível e a rede hidrográfica, ambas na escala de 1:10000, adotando-se a exatidão cartográfica de 0,2 mm. Determinada a dimensão da célula de saída e de posse dos referidos dados, a geração do MDEHC da bacia hidrográfica do ribeirão Lamarão foi realizada utilizando o algoritmo de interpolação Topo to Raster, disponível no módulo Arc Toolbox do software ArcGIS 9.3 (ESRI, 2008). Para a geração do MDEHC a partir desse algoritmo foi realizada a orientação dos arcos da rede hidrográfica no sentido do escoamento e o ajuste da altimetria à hidrografia.

Em seguida, foram realizadas operações de pós-processamento com a finalidade de identificar e eliminar a ocorrência de imperfeições (depressões espúrias) no MDEHC e para criação de uma calha ao longo da rede hidrográfica. De acordo com Nascimento e Silva (2004), Eugenio et al. (2010) e Peluzio, Santos e Fiedler (2010), essas imperfeições são muito frequentes nos MDEs e se derivam de erros presentes nos dados de entrada ou introduzidos no processo de interpolação. As falsas depressões constituem um problema importante na geração de modelos de predição do escoamento, pois interrompem o escoamento superficial. Devem, portanto, ser removidas para se ter um MDE consistente sob o ponto de vista hidrológico. Para o preenchimento dessas imperfeições utilizou-se o comando Fill, disponível no módulo Arc Toolbox do software ArcGIS 9.3.

\section{Delimitação das APPs ao redor das Nascentes e ao longo dos cursos d'água}

Para a delimitação dessas APPs, foram utilizadas as bases de dados correspondentes ao MDEHC, aos pontos relacionados às nascentes e à rede hidrográfica orientada no sentido da foz. Este estudo considerou os cursos d'água como uma única linha para a geração de APPs, desconsiderando, portanto, o ponto de maior cheia como consta no artigo $2^{\mathbf{0}}$, da Resolução $\mathrm{n}^{\mathbf{0}}$ 303 do CONAMA. Além disso, considerou-se que cada início de curso d'água como tendo apenas uma nascente. A delimitação das APPs no entorno das nascentes e das faixas ao longo dos cursos d'água, conforme itens do artigo 3ำ da Resolução no 303 do CONAMA, foi realizada por meio do comando Create Buffer disponível no módulo Arc Toolbox do software ArcGIS 9.3. Sendo que as APPs ao longo dos cursos d'água foram delimitadas com faixas de 30 metros para ambas as margens dos cursos d'águas com largura inferior a 10 metros, em que se enquadram os cursos 
d'água que compõem a bacia de estudo e as APPs das nascentes foram obtidas delimitando-se um raio de 50 metros no entorno das nascentes, superpondo-o às respectivas áreas de contribuição.

\section{Delimitação das APPs de encostas com declividades}

Para a etapa de delimitação das APPs de encostas com declividades acima de 45 graus foi utilizado o MDEHC. Inicialmente, foi elaborado o mapa matricial de declividade da área de estudo utilizando-se o comando Slope, disponível no módulo Arc Toolbox do software ArcGis 9.3. Posteriormente, foi realizada uma reclassificação do mapa de declividade com o objetivo de delimitar apenas a classe de APP superior a 45 graus.

\section{Delimitação das APPs em Topos de Morro}

Para a delimitação dessa classe de APPs, utilizou-se a metodologia descrita por Ribeiro et al. (2002), que consiste na inversão da direção do escoamento do MDHEC objetivando garantir que as depressões situadas sobre essas não fossem identificadas. Após a inversão do escoamento, foram identificados os topos de morro como sendo as depressões, excluindo-se as células que representavam as linhas de cumeada. Esse procedimento objetivou garantir que as depressões localizadas sobre as linhas de cumeada não fossem identificadas como topos de morro.

Após esses procedimentos, é identificada a base do morro, que corresponde à área de contribuição drenada por uma depressão. Determina-se, então, as altitudes da base e do topo do morro por meio das identificações, respectivamente, do menor e maior valor de altitude das células do MDHEC que representam o morro. Dessa forma, foi possível determinar a altura do morro pela diferença entre a altitude do topo do morro e a altitude da sua base.

Após esse procedimento, foram selecionados os morros com altitude entre $50 \mathrm{~m}$ e $300 \mathrm{~m}$ e com declividade superior a 30\%. Para delimitar as áreas de preservação situadas apenas nos topos do morro, calculou-se a relação entre a altura e a altura do topo do morro em relação à base para cada célula do MDHEC o que possibilitou identificar todas as células que possuíam relação igual ou superior a $2 / 3$, correspondentes às APPs de topos de morro.

\section{Análises de conflito de uso da terra}

Para identificação e análise do conflito de uso nas áreas destinadas às APPs foram utilizados os mapas temáticos de uso e ocupação da terra e das categorias de APPs. Na prática, sabe-se que algumas APPs se sobrepõem como é o caso da APP do início dos rios com a APP das nascentes. Neste estudo, a área gerada da APP das nascentes foi calculada e subtraída da parte sobreposta da APP do início dos cursos d'água. Para isto, inicialmente, realizou-se a sobreposição dos mapas de APPs por meio do comando update disponível no módulo Arc Toolbox do ArcGis 9.3 de forma a agrupar as classes de APPs em um único plano de informação, obtendo um mapa final de APPs sem que exista sobreposição das mesmas. Posteriormente, a área ocupada pelas APPs em relação à área da bacia do ribeirão Lamarão, foi calculada executando a função de calculate geometry disponível no módulo Arc Toolbox do ArcGis 9.3. Em seguida, as ocorrências de conflito de acordo com as classes de uso foram identificadas e devidamente mensuradas, confrontando o mapa de uso da terra com o mapa de APPs gerado sem sobreposição com o objetivo de avaliar a porcentagem de ocorrência de cada classe de uso da terra no interior das APPs da área de estudo utilizando o comando clip disponível no módulo Arc Toolbox do ArcGis 9.3. 


\section{Resultados e discussão}

\section{Classes de uso da terra}

A imagem do satélite ALOS, sensor AVNIR-2, bandas 2, 3 e 4, obtida em abril de 2010, e os levantamentos de campo permitiram identificar e mapear 7 classes de uso e ocupação da terra.

Mesmo escolhendo as amostras de treinamento, o resultado da classificação nunca será perfeito; em parte devido às limitações técnicas (do sistema de aquisição), em parte devido à semelhança espectral de determinados componentes da sua imagem (SULSOFT, 2011).

Assim, o resultado obtido com a utilização do estimador de acerto Kappa (matriz de erros) para a classificação realizada, foi de 0,90 , valor considerado excelente $(0,8<$ Kappa $\leq 1)$ (FOODY, 1992), indicando que a classificação alcançou um resultado satisfatório.

Para o levantamento, foram determinadas sete diferentes classes de uso e cobertura da terra, sendo: solo exposto, agricultura, cerrado ralo, cerrado denso, pastagem, pivô central e nuvens. Após o mapeamento das classes as mesmas foram quantificadas conforme o resultado exposto na Tabela 1 e Figura 2.

Solo exposto: Segundo o mapeamento realizado, essa classe ocupa $0,94 \mathrm{~km}^{2}$, o equivalente a 1,01\% da área de estudo.

Agricultura: é a classe dominante na área de estudo e corresponde a toda área cultivada com algum tipo de cultura temporária ou permanente, exceto pastagem e pivô. A área ocupada por essa classe totaliza $46,98 \mathrm{~km}^{2}$ o que equivale a $50,46 \%$ da área total. Quando somada essa classe com a do solo exposto, tem-se um percentual de 51,47\%. Pode-se considerar essa área como sendo a destinada para agricultura na área de estudo. Em relação ao solo e ao relevo, essa categoria possui as mesmas características da área de solo expostos. Sendo esta classe, em determinado período do ano, substituída pela outra.

Cerrado Ralo: fazem parte dessa classe todas as fitofisionomias do Cerrado Aberto, ou Típico, sendo caracterizado por uma mistura de extrato arbustivo e arbóreo. Foram classificados como sendo pertencente a essa classe; Campo Sujo, Campo Rupestre e Cerrado Sentido Restrito. $\mathrm{Na}$ área de estudo, essa classe ocupa atualmente, uma área de $10,50 \mathrm{~km}^{2}$, o que corresponde a $11,28 \%$ da área de estudo.

Cerrado Denso: compreende as feições que englobam as fitofisionomias do Cerrado conhecidas como formações florestais, caracterizadas por possuírem troncos mais eretos e dosséis, mais homogêneos e fechados. Foram classificadas nessa classe as seguintes fitofisionomias: Cerradão, Matas Ciliares e de Galerias. Na área de estudo, essa categoria ocupa, atualmente, uma área de $9,73 \mathrm{~km}^{2}$ ou $10,45 \%$ da área total. Concentra-se principalmente margeando os cursos d'água de todos os tamanhos contidos na área de estudo, em forma de vegetação ripária.

Pastagens: as pastagens totalizam $16,42 \mathrm{~km}^{2}$ ou $17,54 \%$ da área de estudo. Essa classe de uso engloba as espécies de forrageiras destinadas à alimentação animal e congrega todas as espécies de gramíneas, principalmente a brachiaria, espécie africana que se adaptou muito bem em solos do centro-oeste do Brasil.

Pivô Central: Interpretações feitas a partir de imagem AVNIR-2 e apresentadas na Figura 3 evidenciam que na área de estudo existe aproximadamente 12 pivôs e que conforme a Tabela 1 essa classe de uso ocupa uma área de aproximadamente $7,11 \mathrm{~km}^{2}$ que representa $7,63 \%$ da área de estudo.

Nuvens: objetivou-se adquirir imagem com o mínimo possível de presença de nuvens de forma a não prejudicar a avaliação dos conflitos do uso e ocupação da terra na bacia hidrográfica, contudo, por se tratar de um período do ano (início do inverno) em que ainda existe a presença de nuvens no céu, foi criada uma classe para identificar a porcentagem de nuvens na região e verificou-se que elas corresponderam a apenas $1,55 \%$ da área, não comprometendo significativamente a avaliação da área de estudo. 
Figura 2 - Classes de uso da terra da bacia hidrográfica do ribeirão Lamarão, Distrito Federal, Brasil

Figure 2 - Land use classes in the Lamarão river watershed, Federal District, Brazil

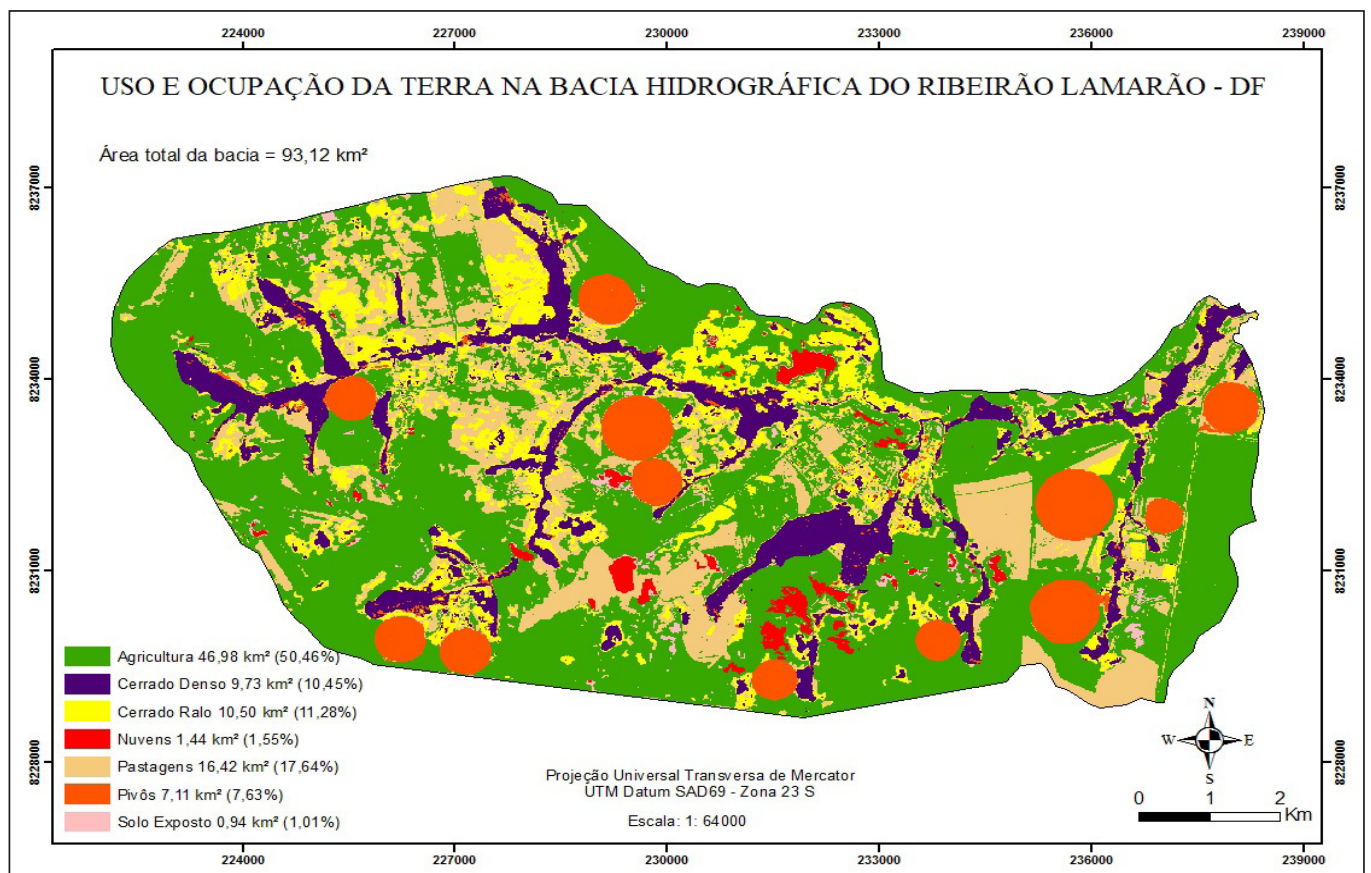

Fonte: Os autores (2012)

Tabela 1 - Classes de uso da terra mapeadas na imagem do satélite ALOS na bacia hidrográfica do ribeirão Lamarão, Distrito Federal, Brasil

Table 1 - Land use classes mapped on the ALOS image, Lamarão river watershed, District Federal, Brazil

\begin{tabular}{lccc}
\hline $\begin{array}{c}\text { Classes de uso } \\
\text { da terra }\end{array}$ & $\begin{array}{c}\text { Área } \\
\left(\mathbf{k m}^{\mathbf{2}}\right)\end{array}$ & $\begin{array}{c}\text { Perímetro } \\
(\mathbf{k m})\end{array}$ & $\begin{array}{c}\text { Área da bacia } \\
\text { ocupada pela classe } \\
(\mathbf{\%})\end{array}$ \\
\hline Agricultura & 46,98 & 876,22 & 50,46 \\
$\begin{array}{l}\text { Cerrado } \\
\text { Denso }\end{array}$ & 9,73 & 327,55 & 10,45 \\
Pivô Central & 7,11 & 258,68 & 7,63 \\
Cerrado Ralo & 10,50 & 826,05 & 11,28 \\
Nuvens & 1,44 & 56,10 & 1,55 \\
Solo Exposto & 0,94 & 118,52 & 1,01 \\
Pastagem & 16,42 & 1020,21 & 17,64 \\
Total & 93,12 & & 100,00 \\
\hline
\end{tabular}

Fonte: Os autores (2012) 
Ao observar o mapa de uso e ocupação da terra na bacia hidrográfica do ribeirão Lamarão - DF (Figura 2) nota-se que a cobertura vegetal natural, representada pelas classes de cerrado denso/ralo, mostra-se concentrada, principalmente, nas proximidades de cursos d'água. $\mathrm{O}$ maior desrespeito à legislação está na ocupação dos terços superiores dos morros praticamente dominados pela classe agricultura e pastagens. A expressiva participação dessas classes na composição da paisagem demonstra os intensos processos de antropização a que a área tem sido submetida.

Campos et al. (2011) ao analisarem adequabilidade do uso agrícola das terras no núcleo Rural do PAD/DF, verificaram que a mesma é caracterizada por uso predominantemente agrícola $(45 \%)$, representada por pastagens e grandes culturas de ciclos anuais como a soja, o milho e o feijão.

\section{Áreas de Preservação Permanente}

A metodologia de delimitação automática das áreas de preservação permanente (APPs) tendo como referência legal o Código Florestal, Lei Federal 4.771/65, a Resolução nº 303, do CONAMA possibilitou identificar e quantificar as categorias de APPs situadas ao longo das margens cursos d'água, nas nascentes e suas respectivas áreas de contribuição, no terço superior dos morros, e nas encostas com declividade superior a 45 graus, estando representadas na Figura 3.

\section{Figura 3 - Mapa das APPs totais da bacia hidrográfica do ribeirão Lamarão, Distrito Federal, Brasil}

Figure 3 - Map of the total PPA's of the Lamarão river watershed, Federal District, Brazil

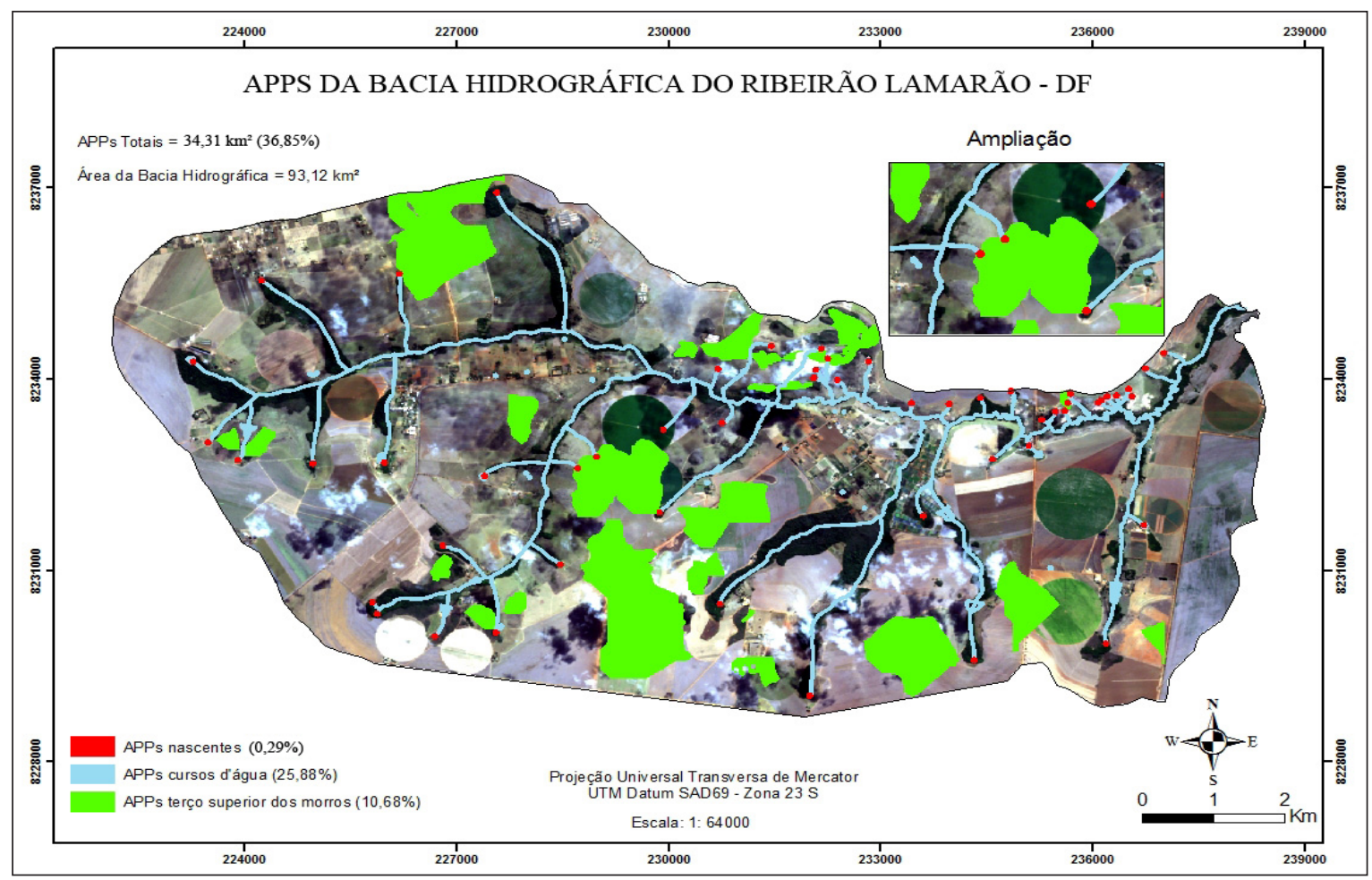

Fonte: Os autores (2012) 
Ao serem analisados os dados da Tabela 2, percebe-se que a maior participação entre as categorias de APPs correspondeu às de cursos d'água (APPS ripárias), 24,10 $\mathrm{km}^{2}$ (70,24\%), distribuídas por aproximadamente 53 cursos d'água, seguida das de topos de morros, $9,94 \mathrm{~km}^{2}$ $(28,97 \%)$ e a das Nascentes, $0,27 \mathrm{~km}^{2}(0,79 \%)$. Nota-se ainda que as APPs ocuparam uma área de $34,31 \mathrm{~km}^{2}$, de um total de $93,12 \mathrm{~km}^{2}$ da área da bacia, representando $36,85 \%$ de áreas legalmente protegidas.

Não foram identificadas APPs em encostas com declividade superior a 45 graus no mapeamento realizado na área de estudo. Por estar localizada no Planalto Central do Brasil, a bacia hidrográfica do Lamarão caracteriza-se pela ocorrência de extensos níveis planos e suaves ondulados (região de chapadas) (GONÇALVES; ROIG; CAMPOS, 2009). Não favorecendo a formação de encostas com declividade superior a 45 graus.

\section{Tabela 2 - Quantificação das APPs na bacia hidrográfica do ribeirão Lamarão, Distrito Federal, Brasil}

Table 2 - Quantification of the PPAs mapped in the Lamarão river watershed, Federal District, Brazil

\begin{tabular}{lcc}
\hline Categoria de APPs & Área $\left(\mathbf{k m}^{\mathbf{2}}\right)$ & $\begin{array}{c}\text { \% área total de } \\
\text { APPs }\end{array}$ \\
\hline Nascentes & 0,27 & 0,79 \\
Cursos d'água & 24,10 & 70,24 \\
$\begin{array}{l}\text { Terço superior dos } \\
\text { morros }\end{array}$ & 9,94 & 28,97 \\
$\begin{array}{l}\text { Encostas com } \\
\text { declividade }>45^{\circ}\end{array}$ & - & - \\
\hline Total Área & 34,31 & 100,00 \\
\hline
\end{tabular}

Fonte: Os autores (2012)

A Figura 4, ilustra que dos $36,85 \%\left(34,31 \mathrm{~km}^{2}\right)$ de áreas legalmente protegidas, $25,88 \%$ consistiram nas categorias de APPs situadas nas margens dos cursos d'água, 10,68\% no terço superior dos morros e $0,29 \%$ nas nascentes e suas respectivas áreas de contribuição. Embora essas categorias correspondam a $36,85 \%$ da área total da bacia hidrográfica do ribeirão Lamarão, apenas $33,46 \%\left(11,50 \mathrm{~km}^{2}\right)$ das áreas legais estão efetivamente protegidas, sendo constituídas pelas classes de ocupação da terra referentes a cerrado denso e ralo.

As APPs de curso d'água garantem a estabilização das margens tendo assim, uma importância vital no controle da erosão do solo e da qualidade da água, evitando o carreamento direto para o ambiente aquático de sedimentos, nutrientes e produtos químicos provenientes das partes mais altas do terreno, os quais afetam a qualidade da água (EUGENIO et al., 2010).

As áreas do entorno das nascentes apresentam suma importância no que diz respeito à vida útil dos rios, uma vez que sem a proteção adequada em torno da mesma nota-se um processo de degradação do rio por ela abastecido. Como verificado por Donadio, Galbiatti e Paula (2005), os quais estudaram quatro nascentes, sendo duas com a presença de vegetação natural remanescente e duas com predominância de atividades agrícolas e concluíram que a presença de remanescentes de vegetação de mata ciliar auxilia na proteção dos recursos hídricos. 


\section{Figura 4 - Quantificação das categorias de APPs na bacia hidrográfica do ribeirão Lamarão, Distrito Federal, Brasil}

Figure 4-Quantification the of PPAs categories in Lamarão river watershed, Federal District, Brazil

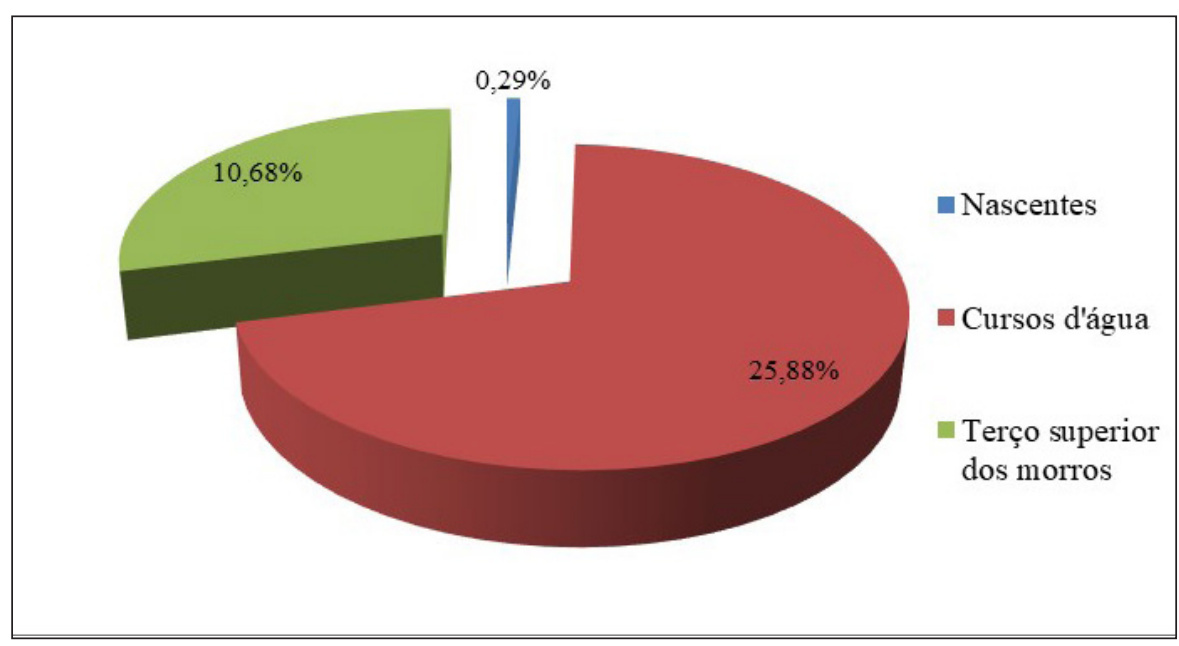

Fonte: Os autores (2012)

Análise dos conflitos no uso da terra na bacia hidrográfica do ribeirão Lamarão DF

De maneira geral, as classes de uso da terra mapeadas estão parcialmente situadas nas áreas legalmente protegidas, principalmente aquelas resultantes de ações antrópicas. Contudo, apenas as classes pertencentes ao sistema antrópico caracterizam o conflito de uso, pois resultam da intervenção humana.

Do total de $34,31 \mathrm{~km}^{2}$ relativos às APPs, $21,70 \mathrm{~km}^{2}$ (63,24\%) estão sendo afetados por algum uso indevido, através de ações antrópicas e a descumprimento da legislação atual. Em $1,13 \mathrm{~km}^{2}$ $(3,30 \%)$ não foi possível identificar a existência de conflitos devido à presença de nuvens. Apenas $33,46 \%\left(11,50 \mathrm{~km}^{2}\right)$ são ocupadas por sistemas fito fisionômicos naturais. Sendo $21 \%$ composto pela classe cerrado denso $\left(7,20 \mathrm{~km}^{2}\right)$ e $13 \%$ pela classe cerrado ralo $\left(4,45 \mathrm{~km}^{2}\right)$.

A análise da Figura 5 mostra que a classe agricultura ocupou a maior parte das APPs, com $38 \%\left(13,04 \mathrm{~km}^{2}\right)$ da área de APPS ocupada irregularmente. Outros conflitos correspondem a áreas protegidas legalmente que se encontram ocupadas pelas classes de pastagens $15 \%$ (5,15 $\left.\mathrm{km}^{2}\right)$, pivô central $8 \%\left(2,75 \mathrm{~km}^{2}\right)$ e solo exposto $2 \%\left(0,69 \mathrm{~km}^{2}\right)$. As áreas de APPs situadas no terço superior dos morros foram claramente as mais afetadas pelos conflitos no uso da terra nas APPs da área de estudo. Por outro lado, observou-se que as áreas ocupadas pela classe de APP referente aos cursos d'água são as menos prejudicadas por ações antrópicas, visto que $21 \%$ (7,20 $\mathrm{km}^{2}$ ) do uso nas áreas de APPs correspondem à classe de cerrado denso, composta por vegetação predominantemente das áreas ripárias.

Considerando as atividades agropecuárias como uma das principais responsáveis pela transformação da paisagem natural, ao se analisar o mapa de uso e ocupação da terra da bacia hidrográfica do ribeirão Lamarão (Figura 3), constatou-se que as classes agricultura (50,46\%), pivô central $(7,63 \%)$ e pastagem $(17,64 \%)$ corresponderam a $75,73 \%$ do uso da terra na bacia hidrográfica. A expressiva participação dessas classes na composição da paisagem demonstra os intensos processos de antropização a que a área tem sido submetida. 


\section{Figura 5 - APPs conservadas e APPs degradadas na bacia hidrográfica do ribeirão Lamarão, Distrito Federal, Brasil}

Figure 5 - Preserves PPA’s and degrades PPA’s in the Lamarão river watershed, Federal District, Brazil

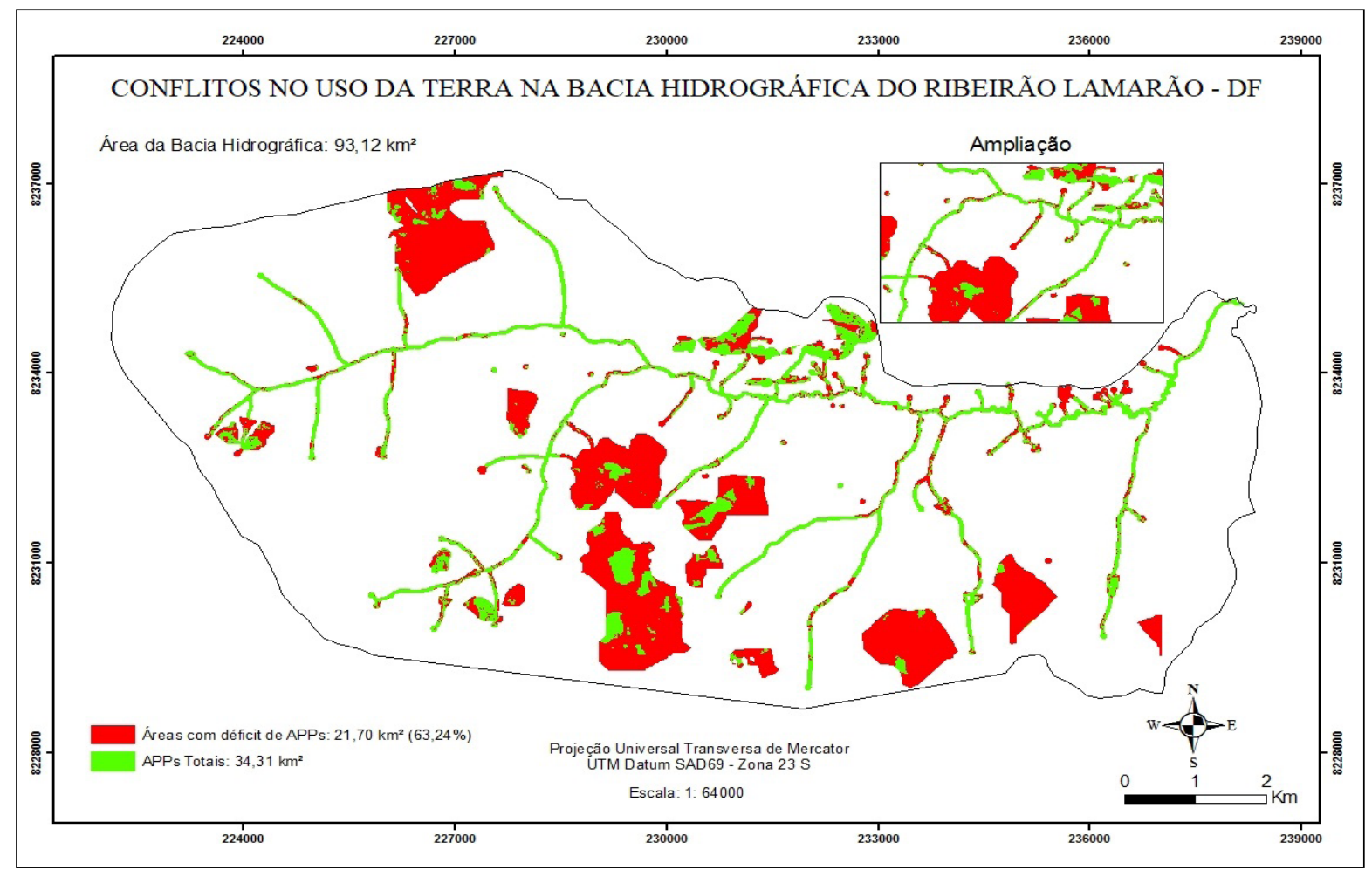

Fonte: Os autores (2012)

As atividades agropecuárias também são a maiores responsáveis pelos conflitos no uso da terra dentro das áreas legalmente protegidas. A Figura 6 quantifica as regiões com déficit de APPs na bacia hidrográfica do ribeirão Lamarão de acordo com a Lei Federal no 4.771/65 e a Resolução no 303, do CONAMA (63,24\%).

Deve-se ressaltar que os quantitativos finais dessa pesquisa condizem com a escala de análise, 1:10000 o que possibilitou uma análise muito mais precisa em relação a estudos realizados utilizando-se de cartas do exército (escala 1:50000) ou dados com resolução espacial em torno dos 90 metros (imagem SRTM). Segundo Hott, Guimarães e Miranda (2005), no caso da delimitação automática das APP, a maior discrepância ocorre quando mapeados os topos de morros e as linhas de cumeadas, pois, quando se utiliza esse tipo de material, as diferenças de nível entre base e cume da elevação não são em parte detectadas. Assim sendo, existe um vínculo entre as escalas de trabalho e os resultados obtidos.

Nesse sentido, alguns estudos envolvendo diferentes escalas evidenciaram tal afirmação, Hott, Guimarães e Miranda (2005) ao analisarem as APPs em topo de morro com mesma metodologia, mas com escala diferentes, sendo uma de 1:250000 tendo como recorte espacial o estado de São Paulo, e outra na escala de 1:50000, tendo como recorte espacial o município de Campinas, depararam com uma diferença em torno de $76 \%$, representado em números absolutos uma redução de $1161 \mathrm{~km}^{2}$ o que corresponde a $4,5 \%$ da área de estudo - município de Campinas - na escala de 1:50.000 para $27 \mathrm{~km}^{2}$ ou 4,4\% da área de estudo - estado de São Paulo - na escala de 1:250000. 
Todavia, esses valores sofrem alterações de acordo com a escala utilizada, isso porque eles são diretamente proporcionais à escala, ou seja, quanto maior a escala, maior o nível de detalhamento e consequentemente, esse detalhamento vai refletir no quantitativo de APPs.

Figura 6 - Quantificação de ocorrência de conflitos no uso da terra nas categorias de APPs delimitadas na bacia hidrográfica do ribeirão Lamarão, Distrito Federal, Brasil

Figure 6 - Quantification of the conflict occurrence land use in PPAs categories mapped in the Lamarão river watershed, Federal District, Brazil

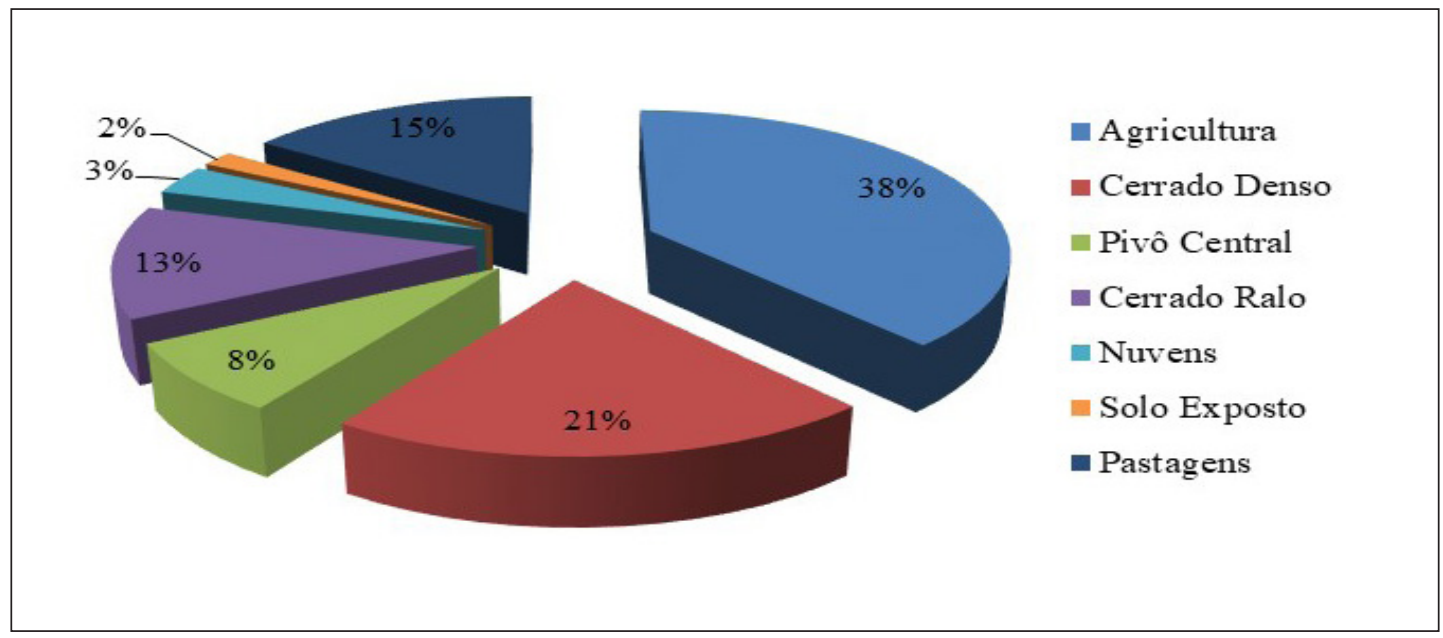

Fonte: Os autores (2012)

O conflito de uso na bacia hidrográfica do ribeirão Lamarão encontra-se em um estado bastante acentuado, com $66,50 \%$ das atividades antrópicas sendo desenvolvidas nas áreas legalmente protegidas pela legislação ambiental. A expressiva participação das classes referentes à agricultura, pivô central e pastagens $(75,73 \%)$ na composição da paisagem demonstra o intenso processo de antropização a que a área tem sido submetida.

As ações antrópicas na bacia causaram diversos problemas ambientais pelo mau uso da terra, necessitando assim de uma política de educação ambiental junto aos agricultores da região, para que, juntamente com um plano de recomposição, possam ser realizadas melhorias nas áreas que tangem projetos de reflorestamento e conservação dos fragmentos florestais já existentes.

\section{Conclusão}

A metodologia adotada mostrou-se eficiente para delimitação automática de APPs, obtendo de forma eficaz e rápida as informações sobre as suas dimensões e distribuição espacial na bacia hidrográfica e na identificação dos conflitos no uso da terra.

As áreas ocupadas por APPs corresponderam a: margens dos cursos d'água $(25,88 \%)$, nascentes e suas áreas de contribuição $(0,29 \%)$ e terço superior dos morros $(10,68 \%)$, ocupando $34,31 \mathrm{~km}^{2}(36,85 \%)$ da área total da bacia hidrográfica do ribeirão Lamarão. Não foram identificadas locais com declividade superior a 45 graus na área de estudo.

Em se tratando dos conflitos de uso da terra, a classe agricultura ocupou (38\%) da área de APPS ocupadas irregularmente. Outros conflitos correspondem a áreas ocupadas pelas classes de Pastagem (15\%), Pivô central (8\%) e Solo exposto (2\%). As APPs situadas no terço superior dos morros foram claramente as mais afetadas, enquanto as APPs de cursos d'água são as menos prejudicadas por ações antrópicas. 


\section{Referências}

AUTODESK. AUTOCAD 2007. USA: AUTODESK, 2006. 2 CDs.

BRASIL. Lei Federal 4.771, de 15 de setembro de 1965. Institui o novo Código Florestal. Disponível em:<HTTP://www.planalto.gov.br/ccivil_03/Leis/L4711.htm>. Acesso em: 15 fev. 2011.

BRASIL. Resolução no 303, de 20 de março de 2002. Dispõe sobre parâmetros, definições e limites de Áreas de Preservação Permanente. Disponível em: <http://www.mma.gov.br>. Acesso em: 12 fev. 2011.

CAMPOS, P. M. et al. Adequabilidade do Uso Agrícola das Terras no Núcleo Rural do PAD/DF. In: SIMPÓSIO BRASILEIRO DE SENSORIAMENTO REMOTO, 2011, Curitiba. Anais... São José dos Campos: INPE, 2011. p. 507-513.

COHEN, J. A. Coefficient of agreement for nominal scales. Educational and Psychological Measurement, [S.1.], v. 20, n. 1, p. 37-46, 1960.

DISTRITO FEDERAL (Brasil). Geografia do DF. Portal do cidadão. [2011a]. Disponível em: $<$ http://www.gdf.df.gov.br/>. Acesso em: 14 fev. 2011.

DISTRITO FEDERAL (Brasil). Secretaria de Meio Ambiente e Recursos Hídricos. Hidrografia. [2011b]. Disponível em: <www.semarh.df.gov.br>. Acesso em: 10 mar. 2011.

DISTRITO FEDERAL (Brasil). SICAD - Sistema Cartográfico do Distrito Federal. Base Cartográfica do DF. Brasília, 1997. Folhas SD. 23-Y-C-IV-4-SE-0C, SD.23-Y-C-IV-4-SE-D, SD.23Y-C-V-3-SO-C, SD.23-Y-C-IV-4-SE-E, SD.23-Y-C-IV-4-SE-F, SD.23-Y-C-V-3-SO-E.

DONADIO, N. M. M.; GALBIATTI, J. A.; PAULA, R. C. Qualidade da água de nascentes com diferentes usos do solo na bacia hidrográfica do córrego Rico, São Paulo, Brasil. Engenharia Agrícola, Jaboticabal, v. 25, n. 1, p. 114-125, 2005.

ENGESAT. [Website]. Curitiba: Engesat, 2011. Disponível em: <www.engesat.com.br>. Acesso em: 10 fev. 2011.

ESRI. The GIS Software Leader | Mapping Software and Data. ArcGis 9.3. California: ESRI, 2008.

EUGENIO, F. C.et al. Confronto do uso e cobertura da terra em áreas de preservação permanente da bacia hidrográfica do rio Alegre, no município de Alegre, ES. Revista Engenharia Ambiental, Espírito Santo do Pinhal, v. 7, n. 2, p. 110-126, 2010.

FERREIRA, C. S. Avaliação temporal do uso e ocupação das terras na bacia do rio São Bartolomeu, DF. 2006. 136 f. Dissertação (Mestrado em Ciências Agrárias) - Universidade de Brasília, Brasília, 2006.

FOODY, G. M. On the compensation for chance agreement in image classification accuracy assessment. Photogrametric Engineering and Remote Sensing, Bethesda, v. 58, n. 10, p. 1459$1460,1992$.

GONÇALVES, T. D.; ROIG, H. L.; CAMPOS, J. E. Sistema de informação geográfica como ferramenta de apoio à outorga dos recursos hídricos subterrâneos no Distrito Federal. Revista Brasileira de Geociências, São Paulo, v. 39, n. 1, p. 169-180, 2009.

HOTT, M. C.; GUIMARÃES, M.; MIRANDA, E. E. Um método para a determinação automática de áreas de preservação permanente em topos de morros para o Estado de São Paulo. In: SIMPÓSIO BRASILEIRO DE SENSORIAMENTO REMOTO, 12., 2005, Goiânia. Anais... São José dos Campos: INPE, 2005. p. 3061-3068

IBGE. Imagens do satélite ALOS, apresentação. Disponível em: <http://www.ibge.gov.br/alos>. Acesso em: 25 jan. 2011. 
ITT CORPORATION. Visual Information Solutions. Envi 4.5. Boulder: ITT, 2008.

LOUZADA, F. L. R. O.; SANTOS, A. R. Conflito do uso e ocupação do solo em APPs da bacia hidrográfica do ribeirão Estrela do Norte- ES. In: ENCONTRO LATINO AMERICANO DE INICIAÇÃO CIENTÍFICA, 13.; ENCONTRO LATINO AMERICANO DE PÓS-GRADUAÇÃO, 9., 2008, João Pessoa. Anais... João Pessoa: Universidade do Vale do Paraíba, 2008.

NASCIMENTO, M. C. et al. Uso do geoprocessamento na identificação de conflito de uso da terra em áreas de preservação permanente na bacia hidrográfica do rio Alegre, ES. Ciência Florestal, Santa Maria, v. 15, n. 2, p. 207-220, 2005.

NASCIMENTO, M. C.; SILVA, P. C. Análise comparativa entre imagens de radar da aeronave de sensoriamento remoto do SIVAM e Ótica do Landsat ETM+. 2001. 36 f. Monografia (Especialização em Geoprocessamento e Zoneamento Geoambiental) - Universidade de Brasília, Brasília, 2004.

PELUZIO, T. M. O.; SANTOS, A. R.; FIEDLER, N. C. (Org.). Mapeamento de áreas de preservação permanente no ArcGis 9.3. Alegre: CAUFES, 2010. 58 p.

RIBEIRO, C. A. A. S. et al. Delimitação automática de áreas de preservação permanente em topos de morros e em linhas de cumeada: metodologia e estudo de caso. In: SEMINÁRIO DE ATUALIZAÇÃO EM SENSORIAMENTO REMOTO E SISTEMAS DE INFORMAÇÕES GEOGRÁFICAS APLICADAS À ENGENHARIA FLORESTAL, 2002, Curitiba. Anais... Curitiba: [s.n.], 2002. p. 7-18.

SANTOS, A. L. F. et al. Mapeamento das áreas de preservação permanente para a bacia do rio Piancó, Estado de Goiás. In: CONGRESSO LATINOAMERICANO Y DEL CARIBE DE INGENIERÍA AGRÍCOLA, 9.; CONGRESSO BRASILEIRO DE ENGENHARIA AGRÍCOLA, 39., 2010, Vitória. Anais... [S.1.]: CONBEA; SBEA, 2010. p. 70-80.

SARTORI, A. A. C. et al. Mapeamento de conflitos de solo em áreas de preservação permanente na Bacia Experimental do Rio Pardo - São Paulo - Brasil. In: SIMPÓSIO BRASILEIRO DE SENSORIAMENTO REMOTO, 14., 2009, Natal. Anais... [S.1.]: INPE, 2009. p. 6197-6202.

SULSOFT. Rotinas do ENVI. ClassEdit. [2011]. Disponível em: <http://www.envi.com.br/ downloads>. Acesso em: 20 dez. 2011. 